\title{
(C) OPEN ACCESS Applying the health action process approach
to bicycle helmet use and evaluating a social
marketing campaign
}

Florian M Karl, ${ }^{1}$ Jennifer Smith, ${ }^{2}$ Shannon Piedt, ${ }^{2}$ Kate Turcotte, $^{2}$ Ian Pike ${ }^{2,3}$

\begin{abstract}
- Additional material is published online only. To view please visit the journal online (http://dx.doi.org/10.1136/ injuryprev-2017-042399).
\end{abstract}

${ }^{1}$ Institute of Health Economics and Health Care Management, Helmholtz Zentrum München $\mathrm{GmbH}$, German Research Center for Environmental Health, Neuherberg, Germany ${ }^{2} \mathrm{BC}$ Injury Research and Prevention Unit, BC Children's Hospital Research Institute, Vancouver, British Columbia, Canada

${ }^{3}$ Department of Pediatrics, Faculty of Medicine, University of British Columbia, Vancouver British Columbia, Canada

\section{Correspondence to} Florian M Karl, Institute of Health Economics and Healthcare Management, Helmholtz Zentrum München (GmbH) - German Research Center for Environmental Health, Ingolstädter Landstraße 1, 85764 Neuherberg, Germany; Florian.karl@helmholtzmuenchen.de

Received 14 March 2017 Revised 2 June 2017 Accepted 28 June 2017 Published Online First 5 August 2017
Check for updates

To cite: Karl FM, Smith J, Piedt S, et al. Inj Prev

2018:24:288-295

\begin{abstract}
Background Bicycle injuries are of concern in Canada. Since helmet use was mandated in 1996 in the province of British Columbia, Canada, use has increased and head injuries have decreased. Despite the law, many cyclists do not wear a helmet. Health action process approach (HAPA) model explains intention and behaviour with self-efficacy, risk perception, outcome expectancies and planning constructs. The present study examines the impact of a social marketing campaign on HAPA constructs in the context of bicycle helmet use.

Method A questionnaire was administered to identify factors determining helmet use. Intention to obey the law, and perceived risk of being caught if not obeying the law were included as additional constructs. Path analysis was used to extract the strongest influences on intention and behaviour. The social marketing campaign was evaluated through t-test comparisons after propensity score matching and generalised linear modelling (GLM) were applied to adjust for the same covariates.
\end{abstract}

Results 400 cyclists aged $25-54$ years completed the questionnaire. Self-efficacy and Intention were most predictive of intention to wear a helmet, which, moderated by planning, strongly predicted behaviour. Perceived risk and outcome expectancies had no significant impact on intention. GLM showed that exposure to the campaign was significantly associated with higher values in self-efficacy, intention and bicycle helmet use.

Conclusion Self-efficacy and planning are important points of action for promoting helmet use. Social marketing campaigns that remind people of appropriate preventive action have an impact on behaviour.

\section{INTRODUCTION}

Bicycle helmets are protective against serious brain injuries caused by bicycle crashes. ${ }^{12}$ In 2010, cycling injury events in British Columbia (BC), Canada, accounted for 19\% $(n=933)$ of transport-related injuries and 20\% $(n=7743)$ of emergency room visits, costing the province millions (\$63 million direct and $\$ 36$ million indirect costs). ${ }^{3}$ Although helmet use is mandatory in some countries and jurisdictions, including BC, numerous people still do not wear a bicycle helmet while cycling. ${ }^{45}$ The 2009 Canadian Community Health Survey reported that $58.8 \%$ of British Columbians report consistent helmet use when cycling. Low rates of compliance with helmet legislation have generated considerable interest in leveraging behavioural theory to improve bicycle helmet use. ${ }^{67}$ Education on, or personal experience with (due to profession or injury history), traumatic brain injuries has been found insufficient to encourage bicycle helmet use. ${ }^{8}$ Instead, strengthening routine and reducing perceived barriers has been shown to improve bicycle helmet use behaviour. $^{6}$

Self-regulatory skills, such as forming an action plan, along with a strategy to cope with possible barriers or challenges, impact the adoption and maintenance of simple protective behaviours like wearing a helmet. ${ }^{9}$ A person who intends to wear a helmet must decide on where, when and how to wear the helmet, as well as believe in his or her ability to successfully carry out this plan and overcome any obstacles or inconveniences that arise. The health action process approach (HAPA) model of health behaviour change incorporates planning and coping skills as moderators in the transition between forming the intention to adopt a health behaviour, to translating that intention into sustained action; therefore, the HAPA is an appropriate model to apply to helmet use behaviour in order to gain a better understanding of why compliance rates are low. ${ }^{9}$

The HAPA model integrates social-cognitive theory and the theory of reasoned action with other phase-oriented volition theories. ${ }^{10-12}$ This fusion has resulted in a stage theory with two distinct phases: a preintentional phase encompassing motivational processes (intention forming), and a postintentional phase describing volitional processes (translating intention into action). ${ }^{13}$ Preintentional factors that impact intention formation are risk perception, outcome expectancies and (action) self-efficacy. ${ }^{14}$ After the intention has been formed, postintentional factors such as coping and planning are necessary for transforming an intention into action. ${ }^{13}$

\section{Applying HAPA constructs to bicycle helmet use behaviour}

A person may intend to wear a helmet due to a perceived high risk of head injury when cycling, and believe in the protective benefits of helmet use. To manage wearing a helmet each time, this person forms plans for how to carry or store the helmet between bike rides, and how to cope with messy hair after wearing the helmet. This study evaluates the degree to which risk perception, outcome expectancies, planning and coping allow for accurate prediction of consistent helmet use among cyclists, and the effect of a social marketing 
campaign on key HAPA constructs. Because bicycle helmet use is mandated by law in $\mathrm{BC}$ for all ages, perceived risk of being caught breaking the law is included in this study as a preintentional predictor of helmet use.

\section{The community against preventable injuries campaign: 'Preventable'}

Launched in the summer of 2009, Preventable is an ongoing, province-wide social marketing campaign reminding British Columbians to 'have a word with yourself' before engaging in behaviour at work, home or play that has the potential to result in injury. Ambient (outdoor or indoor) signage, mass media (including social media) and guerrilla messaging reach its audience at the critical moment of decision, when intentions are translated into actions, to trigger a series of cognitions in the planning process that will lead to the adoption of safer behaviours. ${ }^{15}$ Although Preventable objectives broadly address all injury types, campaign activities have included messages targeted to cyclists about helmet use and crash prevention. Awareness of Preventable and key campaign slogans is explored in this study as an additional influence on HAPA constructs and helmet-wearing behaviour.

\section{METHODS}

\section{Participants}

An equal number of male and female adults were invited thru email to participate in the study through an online research panel provider in BC. The target population was adults between the ages of 25 and 54 years, weighted by the proportional population within each of the five health authority service delivery regions in $\mathrm{BC}$ to achieve the most representative sample possible. A preliminary screening question was displayed to those respondents who opened the survey link. Panellists who indicated bicycle use at least once or twice a year were eligible for the study and automatically redirected to the questionnaire. Four hundred cyclists $(n=400)$ in BC were included in the study.

\section{Materials}

A 36-item questionnaire was developed to incorporate existing formulations from other studies using HAPA and HAPA-related models. ${ }^{91316-19}$ Participants were first asked about bicycle ownership and time spent cycling. Table A.1 in online supplementary file 1 displays the items used to assess risk perception, outcome expectancies, self-efficacy, intentions, planning, behaviour and perceptions around enforcement of helmet laws. Demographic information as well as exposure to campaign messages was also collected.

\section{Data analysis}

First, factor analysis was applied to verify consistency between factors included the HAPA model using $\mathrm{R}$ Studio packages 'lavaan' and 'semPlot'. ${ }^{20-22}$ 'Psych' package was used to calculate Cronbach's alpha. ${ }^{23}$ Path analysis tested the predictive power of each variable in the structured model. The standardised root mean square residual (SRMR) was used in combination with the comparative fit index (CFI) to compare the models and evaluate overall fit. ${ }^{24}$ Cut-off values of CFI $<0.95$ and SRMR $>0.07$, with an acceptable type 1 error rate of 10 , were selected as per $\mathrm{Hu}$ and Bentler. ${ }^{24}$

Because the Preventable campaign had been active throughout $\mathrm{BC}$ for over 7 years prior to the study period, propensity score matching (PSM) was used to compensate for the lack of a true control group by matching participants on as many potentially confounding factors as possible, and reveal any difference in behaviour between those who have seen the campaign and those who have not. ${ }^{25}$ A participant was considered 'campaign exposed' when he or she answered one of the following questions positively: "Are you aware of a social marketing campaign with the slogan 'Have a word with yourself'?" or "Are you aware of a social marketing campaign with the slogan 'Seriously?'?". Each campaign-exposed participant was matched to an unexposed participant by age, sex, education, marital status, employment status, region of residence, average amount of time on a bicycle (daily, weekly, and so on), type of cyclist (occasional, sport, recreational, and so on), having children under 16 years of age and personal or familial hospitalisation during the last 12 months. PSM was performed as a 1:1 matching with replacement to maximise matching quality and minimise bias. ${ }^{26} 27$

Lastly, generalised linear modelling (GLM) was then executed on the complete sample to examine the effect of the unique campaign periods on helmet use behaviour. The same covariates were used for both GLM and PSM. A Gaussian distribution with identity link was assumed for the analysis. T-tests were then used to compare campaign exposed and unexposed groups after matching.

\section{Ethics statement}

This study was approved by the UBC Research Ethics Board (certificate \#H15-03012). All participants gave their written informed consent.

\section{RESULTS}

\section{Health action process approach}

Comparison of HAPA model (model A, figure 1) and a trimmed HAPA model (model B, figure 2) found model A inferior to model B. Model A included factors that did not predict behaviour as expected, such as risk perceptions, outcome expectancies and postintentional self-efficacy (maintenance and recovery), and did not demonstrate an acceptable overall fit. Model B, which includes action self-efficacy, intention to comply with the law, intention to wear a helmet, planning and helmet use, explained approximately $83 \%$ of behaviour $\left(\mathrm{R}^{2}=0.83\right)$ and showed an acceptable overall fit $(\mathrm{CFI}=0.95, \mathrm{SRMR}=0.036)$. The moderation of intention to wear a helmet through planning was significant, with an indirect effect coefficient $\left(\beta_{\text {(Intention } \rightarrow \text { Plan- }}\right.$ $\left.{ }_{\text {ning)* }} \beta_{(\text {Planning } \rightarrow \text { helmet use })}\right)$ of $0.05(\mathrm{p}<0.001)$, leading to a total effect $\left(\beta_{\text {(Intention } \rightarrow \text { Helmet use) }}+\beta_{\text {(indirect effect) }}\right)$ of $0.49(\mathrm{p}<0.001)$. Factor analysis demonstrated loadings between 0.50 and 0.99 , with values of Cronbach's alpha between 0.69 and 0.99 . Detailed results of the factor analysis and model comparison can be reviewed in online appendix tables A.2 and A.3.

\section{Cycling characteristics and PSM matching}

Of the 400 survey respondents, 265 (66\%) were male and 135 (34\%) were female. Demographic characteristics were evenly distributed across all subsamples measured. Two hundred and fifteen (54\%) individuals had heard of at least one of the campaign slogans, 201 (50\%) were familiar with the slogan 'have a word with yourself' and 133 (33\%) recalled 'seriously?'. Of the campaign-exposed individuals, $63.2 \%$ indicated that they always wear a helmet and only 5.6\% said they never wear a helmet. Among campaign-unexposed participants these values were $53.0 \%$ and $7.6 \%$, respectively. Demographic characteristics of survey participants are displayed in table 1 . While the subgroups shown in table 1 did not demonstrate significant variation, application of PSM further minimised differences from $11 \%$ to 


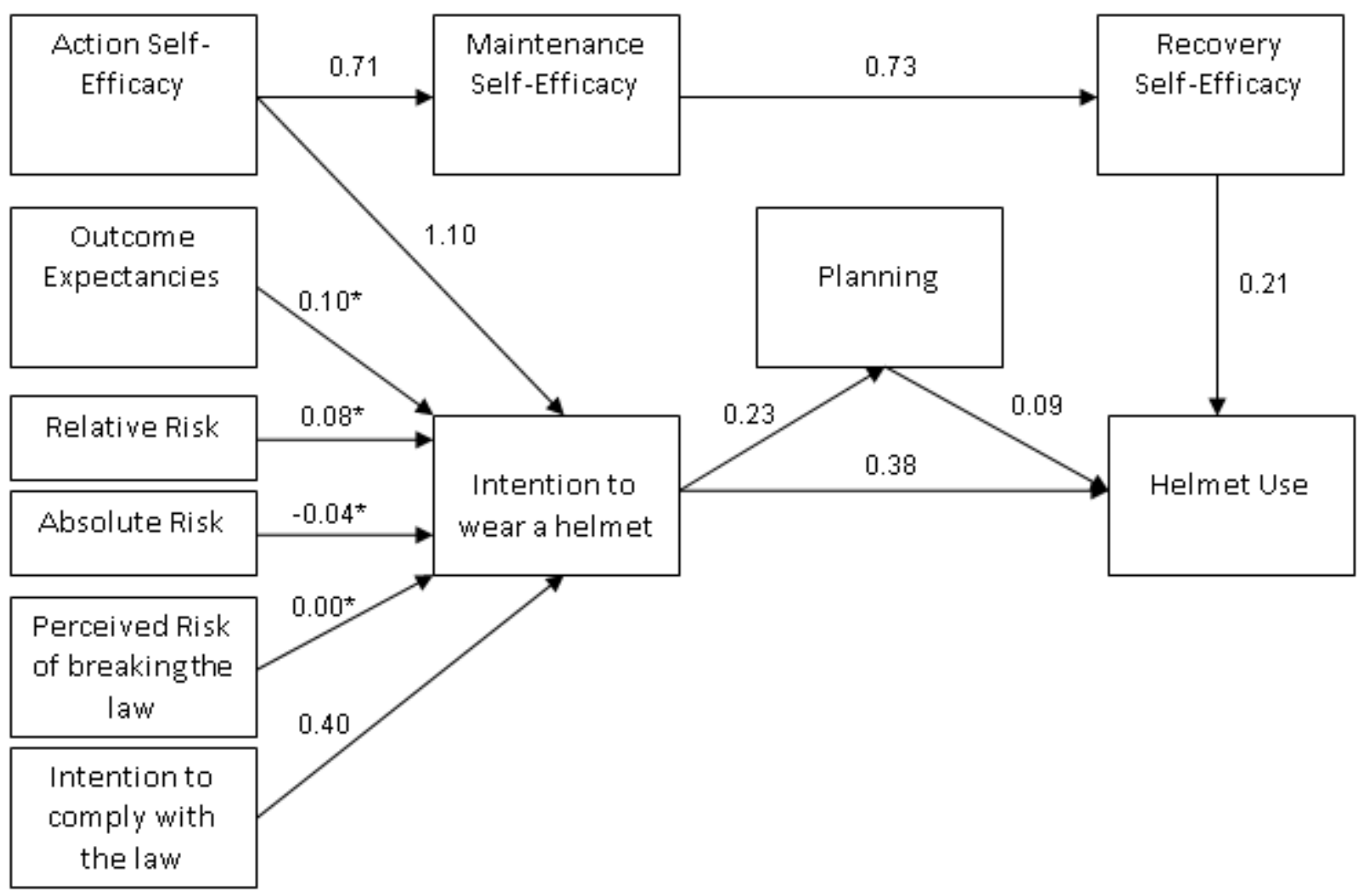

Figure 1 Model A.

$0.001 \%$ (figure 3). During this process, 215 exposed individuals were eventually matched to 95 of 185 possible controls. Detailed PSM results can be reviewed in the online supplementary appendix table A.4.

\section{Impact of Preventable}

GLM analysis of exposure to the individual campaign slogans revealed some differences in the strength of their association to the factors of model B that were not likewise revealed by t-tests (tables 2 and 3). Familiarity with the slogan 'have a word with yourself' was positively associated with action self-efficacy, intention to wear a helmet and planning, although awareness of the campaign slogan 'seriously?' did not show such strong associations. In addition to campaign exposure, cycling frequency was strongly connected to model B factors. Strikingly, less frequent cyclists demonstrated higher values among the behaviour-explaining variables and helmet use than did daily cyclists. Lastly, the model showed that being male was associated with less planning.

\section{DISCUSSION}

This paper is the first to apply the HAPA model in the context of bicycle helmet-wearing behaviour. The best fit was found when 'Action self-efficacy', 'Intention to comply with the law', 'Intention to wear a helmet' and 'Planning' were included in the model. Thus, neither perceived risk of injury nor perceived risk of getting caught breaking the law significantly impacted the model, which was somewhat unexpected. ${ }^{19}{ }^{28}$ However, this finding may be the result of differing information bases for interpreting the survey questions about risk perception. For example, survey respondents who consistently wear helmets may have scored low on risk perception measures because when weighing their risk of sustaining a head injury, they were taking into

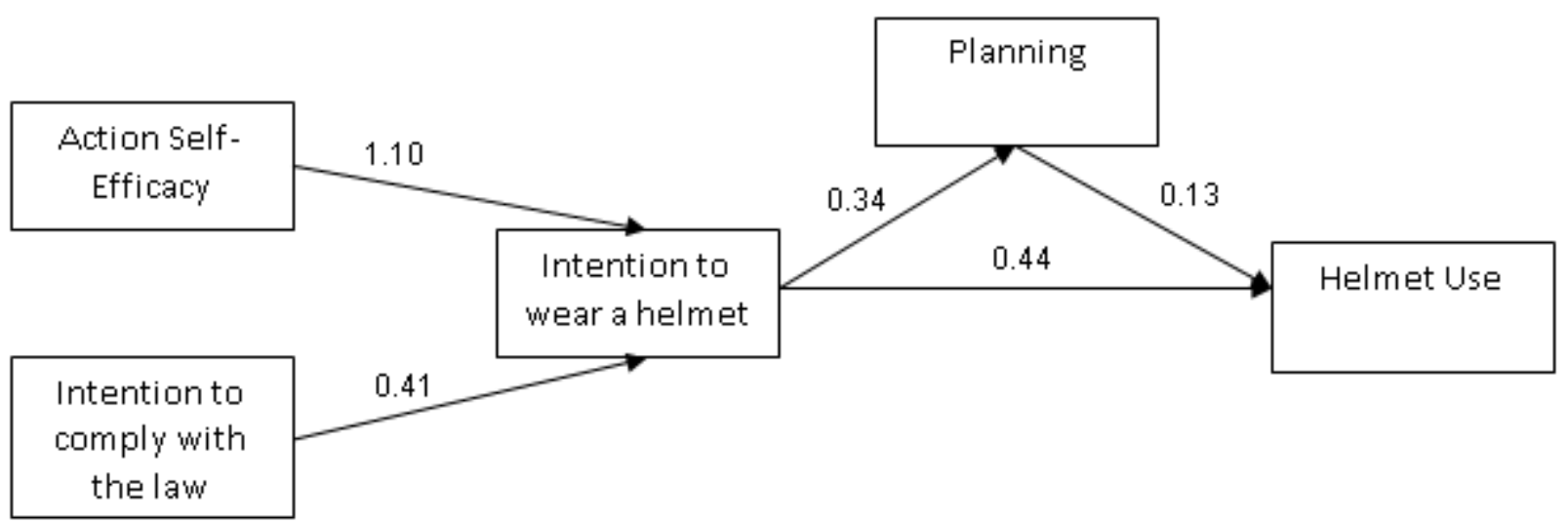

Figure 2 Model B. 
Table 1 Participant characteristics

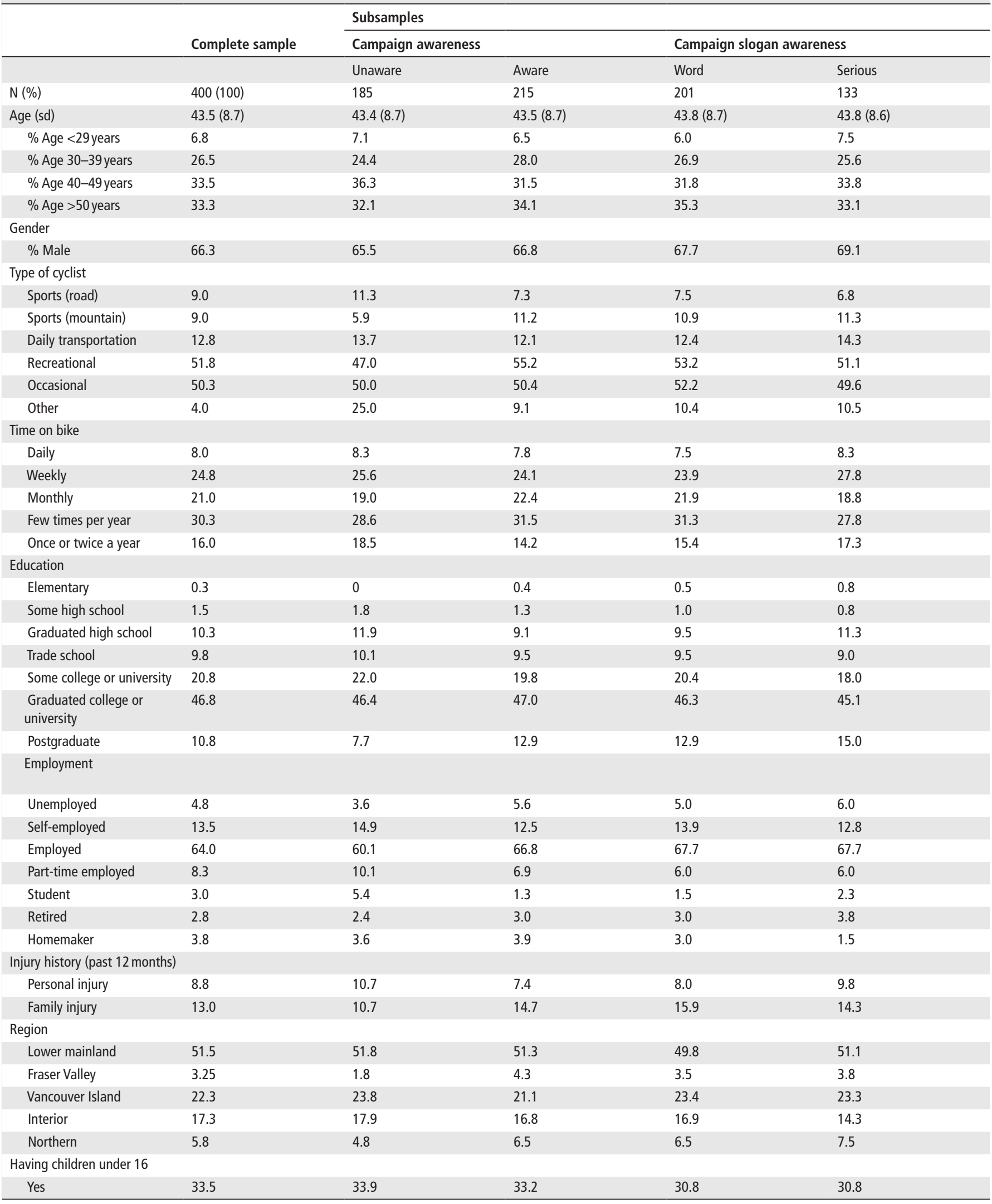

'Type of Cyclist' adds up to over $100 \%$ because participants could select more than one type of cycling activity. Aware: participants who remembered at least one of the campaign slogans. Unaware: participants who did not remember at least one of the campaign slogans, Word: people who remembered the slogan 'have a word with yourself.' Serious: people who remembered the slogan 'seriously?'. 


\section{Unmatched Treatment Units}

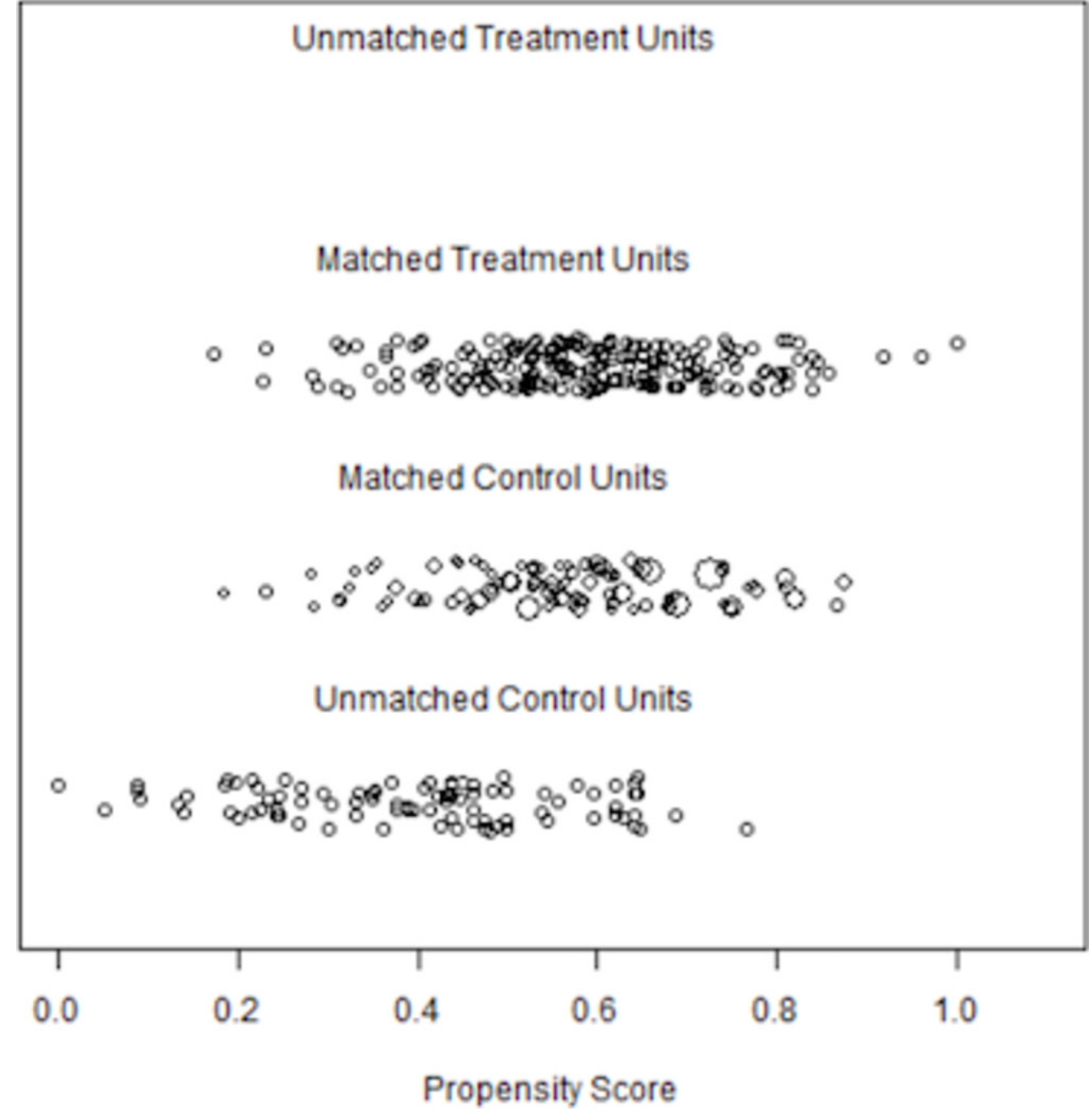

Figure 3 Propensity score matching results.

account that they wear a helmet as a protective measure. Other respondents who consistently wear helmets may have scored high on risk perception measures because they were responding to a general sense of vulnerability to injury that prompts them to take protective measures (including wearing a helmet) when cycling. An equal balance between these points of view could have been a reason for the very small beta coefficients. Therefore, the impact of risk perception on behavioural outcomes in the context of helmet use for cycling requires more study, but the results of the present research indicate probability of success in modifying helmet use behaviour when self-efficacy or planning skills are enhanced. Because planning had significant effects, both direct and indirect, on helmet use behaviour within the model, we suggest that strengthening planning skills should be a focus of future helmet use campaigns and related interventions. Further, the present study revealed gender differences in planning. Interventions aimed at improving planning skills might pay particular attention to the male component of the target group.

As an intervention, the Preventable campaign targets British Columbian adults in the time and place of highest risk for injury with messaging designed to interrupt and reset the planning process. While mass media and guerrilla stunts raise public awareness of the issue of preventable injuries that happen at home, at work, at play and on the road, the heart of the campaign is messaging that is strategically placed as close as possible to moments of risk. Although the campaign broadly addresses preventable injuries of many types, cycling injuries have been included in past campaign activities. Some examples of strategic placement include signage along popular cycling routes, transit shelter ads, branded helmets locked to parked bicycles or signage on the bicycle racks themselves. The message 'Before you think you won't need a helmet today, have a word with yourself' or 'Biking without a helmet? Seriously?' implies the risks of cycling without a helmet, and provides the reminder in a relevant moment.

The slogan 'have a word with yourself' reminds people to reflect on their plan of action before taking a risk. ${ }^{15}$ The campaign slogan was developed out of formative evaluative research that indicated the target audience possessed sufficient knowledge about preventing injuries, so only a timely reminder would be needed. The slogan invokes this knowledge at the critical moment of decision, when the intention to perform a potentially unsafe behaviour is translated into action. Cognitions in this transitional phase are interrupted and reset, which allows for an opportunity to harness self-efficacy beliefs and incorporate safety measures into the action plan.

GLM results showed that the Preventable campaign slogan 'have a word with yourself' affected planning, action self-efficacy, 
Table 2 T-test results comparing exposed to unexposed participants before and after PSM

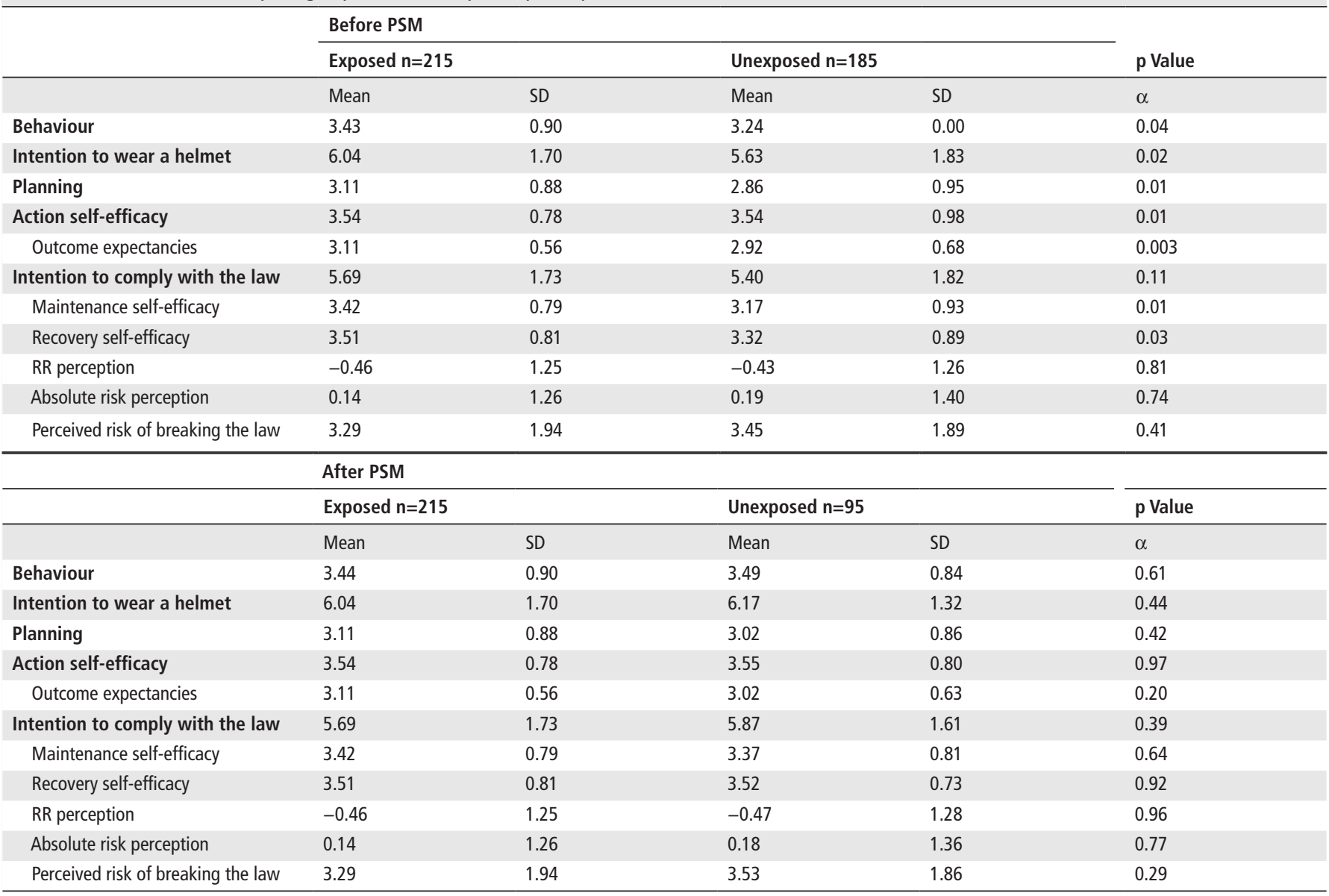

Factors within the best fitting model (model B) are printed bold. Exposed: people who answered at least one of the questions on campaign exposure with 'yes.' Unexposed: people who answered all questions on campaign exposure with 'no.'

PSM, propensity score matching.

intention to wear a helmet, as well as behaviour. The slogan 'seriously?' did not explain a significant increase in these factors, although this is likely due to the shorter period of time that this slogan has been in market.

The present study also found that action self-efficacy predicted helmet use within the trimmed HAPA model. Consistent with these results, the relationship between action self-efficacy and helmet use has been previously described as a positive association. ${ }^{6}$ Action self-efficacy is an optimistic belief necessary to build motivation. People with higher self-efficacy imagine the success of an action and so are more likely to initiate a new behaviour. Therefore, the results of this study provide evidence in support of interventions that enhance action self-efficacy to promote bicycle helmet use.

Lastly, all factors, with the exception of planning, were associated with the frequency of bicycle use. The study showed that daily use was associated with lower values in measures of behaviour, intention to wear a helmet and action self-efficacy. This seems counterintuitive, but it might also be interpreted as a reflection of daily bicyclists' experience-they are not able to always wear their helmets-and so have lower self-efficacy, less intention to comply with the law and less intention to wear a helmet. This finding implies the need to facilitate and promote helmet use among frequent cyclists.

The present study was subject to some limitations. Cyclists who wear helmets may be more likely to pay attention to Preventable campaign messages. However, a sufficiently large study sample was drawn from areas representative of the $\mathrm{BC}$ population and a very low threshold of cycling frequency was set for inclusion in the study. Gender was unevenly distributed in the sample, which could be an indication of selection bias. However, the data did not suggest any uneven bias between subgroups. Therefore, any biases would affect the overall values but not the differences between the groups. Still, the results of the campaign evaluation are robust as PSM and GLM were applied to adjust for potentially confounding variation within the study population. While the comparison of exposed and unexposed individuals after PSM did not show significant differences, this may be due to some limitations inherent in PSM. ${ }^{28}$ The most important criterion for a successful application of PSM is a rich set of covariates, which was considered satisfied in the current study. However, there is always the chance of model misspecification. ${ }^{27}$ Further, because there were too few unexposed participants to act as controls, we had to allow replacement during the matching process, consequently comparing only 95 of 185 possible controls, which in turn increases the chance of misspecification.

\section{CONCLUSION}

The current study identified a strong association between action self-efficacy, planning and behaviour. The slogan 'have a word with yourself' from the Preventable social marketing campaign was related to higher values within these factors. Therefore, future social marketing campaigns should focus on action 


\section{Original article}

Table 3 Generalised linear modelling regression coefficients within key health action process approach constructs

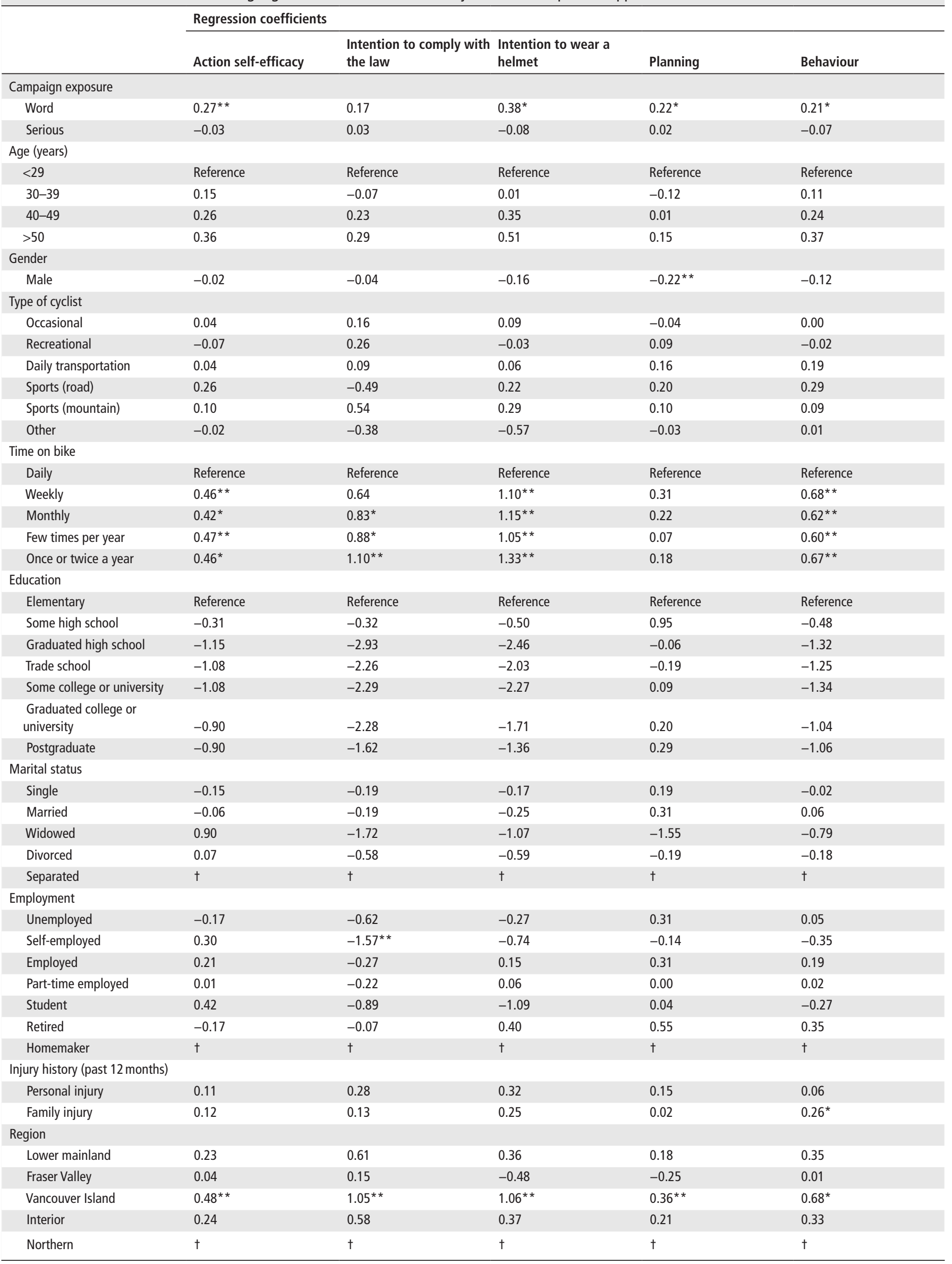




\begin{tabular}{cllll}
\hline & \multicolumn{2}{l}{ Regression coefficients } & & \\
\cline { 2 - 5 } & Action self-efficacy & $\begin{array}{l}\text { Intention to comply with } \\
\text { the law }\end{array}$ & $\begin{array}{l}\text { Intention to wear a } \\
\text { helmet }\end{array}$ & Planning \\
\hline $\begin{array}{c}\text { Having children under 16 } \\
\text { Yes }\end{array}$ & 0.00 & 0.10 & 0.10 & 0.14 \\
\hline
\end{tabular}

*Significant on a level of $p<0.10$; * Significant on a level of $p<0.05$.

†Not calculated due to singularities.

\section{What is already known on the subject}

- Urisdictions that legislate mandatory bicycle helmet use have lower rates of head injuries associated with cycling

- The HAPA model of health behaviour change indicates that risk perception, self efficacy, and outcome expectancies affect intention and behaviour and the transition between the two is moderated by planning

\section{What this study adds}

- Planning and action self efficacy are important targets for interventions aimed at increasing bicycle helmet use

- The existing social marketing campaign in British Columbia called, Preventable, is affecting attitudes and behaviours related to helmet use among cyclists in the target population

self-efficacy and planning as points of action, and might usefully draw on elements of the successful approach of Preventable.

Contributors All authors contributed significantly to the paper and that the final version of the paper has also been seen and approved by all authors in an internal review process. FMK and IP have contributed substantially to the study design and acquisition and analysis/interpretation of the data. FMK drafted the article with assistance from KT and SP, and both IP and JS have extensively reviewed and revised the article critically for important intellectual content. Neither the article nor any of its essentials have been published or are submitted for publication elsewhere.

Competing interests IP is the coexecutive director and spokesperson for Preventable.

Ethics approval University of British Columbia Research Ethics Board (certificate \#H15-03012).

Provenance and peer review Not commissioned; externally peer reviewed.

Open access This is an open access article distributed in accordance with the Creative Commons Attribution Non Commercial (CC BY-NC 4.0) license, which permits others to distribute, remix, adapt, build upon this work non-commercially, and license their derivative works on different terms, provided the original work is properly cited and the use is non-commercial. See: http://creativecommons.org/ licenses/by-nc/4.0/

(c) Article author(s) (or their employer(s) unless otherwise stated in the text of the article) 2018. All rights reserved. No commercial use is permitted unless otherwise expressly granted.

\section{REFERENCES}

1 Cripton PA, Dressler DM, Stuart CA, et al. Bicycle helmets are highly effective at preventing head injury during head impact: head-form accelerations and injury criteria for helmeted and unhelmeted impacts. Accid Anal Prev 2014;70:1-7.

2 Vassilyadi M. Wear your Bicycle Helmet!. Can I Neurol Sci 2016;43:3-4.
3 Rajabali FIA, Barnett B, Pike I. Economic Burden of Injury in Britsih Columbia. Vancouver, BC: BC Injury Research and Prevention Unit, 2015.

4 Molina-García J, Queralt A. The impact of Mandatory Helmet-Use legislation on the frequency of Cycling to School and Helmet Use among Adolescents. J Phys Act Health 2016;13:649-53

5 Macpherson AK, To TM, Macarthur C, et al. Impact of mandatory helmet legislation on bicycle-related head injuries in children: a population-based study. Pediatrics 2002;110:e60.

6 O'Callaghan FV, Nausbaum S. Predicting bicycle helmet wearing intentions and behavior among adolescents. J Safety Res 2006;37:425-31.

7 Uibel S, Müller D, Klingelhoefer D, et al. Bicycle Helmet use and non-use - recently published research. J Occup Med Toxicol 2012;7:9.

8 Jung CS, Zweckberger K, Schick U, et al. Attitude and opinion of neurosurgeons concerning protective bicycle-helmet use. J Neurotrauma 2010;27:871-5.

9 Schwarzer R. Modeling Health Behavior Change: how to predict and modify the adoption and maintenance of Health Behaviors. Appl Psychol 2008;57:1-29.

10 Bandura A. Social foundations of thought and action: a social cognitive theory. Prentice-Hall, Inc, 1986.

11 Fishbein M, Ajzen I. Belief, attitude, intention, and behavior: an introduction to theory and research, 1977.

12 Heckhausen H. Motivation and action: springer Science \& Business Media, 2012.

13 Schwarzer R, Luszczynska A. How to overcome health-compromising behaviors: the health action process approach. European Psychologist 2008;13:141-51.

14 Luszczynska A, Schwarzer R, Lippke S, et al. Self-efficacy as a moderator of the planning-behaviour relationship in interventions designed to promote physical activity. Psychol Health 2011;26:151-66.

15 Pike I, Piedt S, Lafreniere K. 337? Social marketing to reduce preventable injuries in BC, Canada. Injury Prevention 2016;22(Suppl 2):A123.3-A124.

16 Luszczynska A, Schwarzer R, Planning SR. Planning and Self-Efficacy in the adoption and maintenance of breast Self-Examination: a longitudinal study on Self-Regulatory cognitions. Psychol Health 2003;18:93-108.

17 Schwarzer R, Jerusalem M. The general self-efficacy scale (GSE). Anxiety, Stress, and Coping 2010;12:329-45.

18 Ruedl G, Kopp M, Rumpold G, et al. Attitudes regarding ski helmet use among helmet wearers and non-wearers. Inj Prev 2012;18:182-6.

19 Brijs K, Brijs T, Sann S, et al. Psychological determinants of motorcycle helmet use among young adults in Cambodia. Transportation Research Part F. Traffic Psychology and Behaviour 2014;2690:273-.

20. Studio R. RStudio: integrated development environment for R. Boston, Massachusetts: RStudio Inc, 2012.

21 Rosseel Y. lavaan: an R package for structural equation modeling and moreVersion 0.4-9 (BETA). Belgium: Department of Data Analysis, Ghent University, 2011.

22 Epskamp S. semPlot: path diagrams and visual analysis of various SEM packages' output. $R$ package version 2013;03:2.

23 Revelle W. Psych: Procedures for personality and psychological research. 1. Northwestern University: Evanston R package version, 2014.

$24 \mathrm{Hu}$ Li-tze, Bentler PM. Cutoff criteria for fit indexes in covariance structure analysis: conventional criteria versus new alternatives. Struct Equ Modeling: A Multidiscip J 1999;6:1-55.

25 Randolph JJ, Falbe K, Manuel AK, et al. A step-by-step guide to propensity score matching in R. Pract Assess, Res Eval 2014;19:2.

26 Caliendo M, Kopeinig S. Some practical guidance for the implementation of propensity score matching. J Econ Surv 2008;22:31-72.

27 De H, Imai K, King G, et al. Matching as nonparametric preprocessing for reducing model dependence in parametric causal inference. Political analysis 2007;15:199-236.

28 Imai K, Ratkovic M. Covariate balancing propensity score. J Royal Statisti Soc: Series B 2014;76:243-63. 